\title{
Retraction
}

\section{Retracted: The Copper Radioisotopes: A Systematic Review with Special Interest to ${ }^{64} \mathrm{Cu}$}

\section{BioMed Research International}

Received 1 May 2018; Accepted 1 May 2018; Published 8 July 2018

Copyright (C) 2018 BioMed Research International. This is an open access article distributed under the Creative Commons Attribution License, which permits unrestricted use, distribution, and reproduction in any medium, provided the original work is properly cited.

BioMed Research International has retracted the article titled "The Copper Radioisotopes: A Systematic Review with Special Interest to ${ }^{64} \mathrm{Cu}$ " [1]. The article was found to contain a substantial amount of material from the following published articles:

(i) Szymański et al. [2], which is cited as reference [4].

(ii) Wadas et al. [3], which is cited as reference [3].

(iii) Carolyn and Ferdani [4], which is cited as reference [54].

(iv) Smith et al. [5], which is cited as reference [34].

\section{References}

[1] A. Niccoli Asabella, G. L. Cascini, C. Altini, D. Paparella, A. Notaristefano, and G. Rubini, "The copper radioisotopes: a systematic review with special interest to ${ }^{64} \mathrm{Cu}$," BioMed Research International, vol. 2014, Article ID 786463, 9 pages, 2014.

[2] P. Szymański, T. Fraczek, M. Markowicz, and E. MikiciukOlasik, "Development of copper based drugs, radiopharmaceuticals and medical materials," BioMetals, vol. 25, no. 6, pp. 10891112, 2012

[3] T. Wadas, E. Wong, G. Weisman, and C. Anderson, "Copper Chelation Chemistry and its Role in Copper Radiopharmaceuticals," Current Pharmaceutical Design, vol. 13, no. 1, pp. 3-16, 2007.

[4] J. Carolyn and R. Ferdani, "Copper-64 Radiopharmaceuticals for PET Imaging of Cancer: Advances in Preclinical and Clinical Research," Cancer Biotherapy \& Radiopharmaceuticals, 2009.

[5] N. A. Smith, D. L. Bowers, and D. A. Ehst, "The production, separation, and use of $67 \mathrm{Cu}$ for radioimmunotherapy: A review," Applied Radiation and Isotopes, vol. 70, no. 10, pp. 2377-2383, 2012. 